\title{
APLIKASI PENILAIAN KINERJA DOSEN BERBASIS ANDROID
}

\author{
Iwan Lesmana, M.Kom ${ }^{1)}$, Dede Irawan, M.Kom ${ }^{2)}$ \\ Dosen Fakultas Ilmu Komputer Universitas Kuningan ${ }^{1), 2)}$ \\ Jl. Cut Nyak Dhien No.36A Cijoho Kuningan - Jawa Barat \\ E-mail : $\underline{\text { iwanlesmana@uniku.ac.id }{ }^{1}{ }^{1} \text {, dede.irawan@uniku.ac.id }}{ }^{2)}$
}

\begin{abstract}
ABSTRAK
Evaluasi dosen merupakan cara untuk mengetahui pengaruh pengajaran dosen terhadap mahasiswa, yaitu proses penilaian dari persiapan mengajar, materi pembelajaran, penyampain materi ajar, kompetensi dosen, pengelolaan kelas dan evaluasi pemebelajaran. disamping penilain dari mahasiswa, penilaian dosen yang dilakukan program studi dianggap penting untuk melihat kinerja dosen. Dalam penelitian ini membangun sebuah aplikasi untuk mengevaluasi atau menilai kinerja dosen. Dalam penelitian ini metode yang digunakan yaitu RAD (Rapid Application Development) dikarenakan penyusunan aplikasi hanya membutuhkan waktu sekitar 6 bulan dan untuk pengembangan sistemnya megunakan UML (Unified Modelling language). Penerapan aplikasi ini ada dua metode akses yakni melaui smatphone android dan desktop untuk level administrator dan Program Studi. Sedangkan penelitian ini dilaksanakan di Universitas Kuningan
\end{abstract}

Kata Kunci : Evaluasi Dosen, RAD, UML, Smartphone, Android, Universitas Kuningan

\section{ABSTRACT}

Lecturer's evaluation is a way to know the influence of lecturers' teaching on the students, the assessment process of the teaching preparation, the learning material, the teaching material presentation, the lecturer competence, the class management and the evaluation of the learning. in addition to the assessment of the students, the assessment of lecturers conducted study program is considered important to see the performance of lecturers. In this study build an application to evaluate or assess the performance of lecturers. In this research the method used is RAD (Rapid Application Development) due to the preparation of the application only takes about 6 months and for the development of the system megunakan UML (Unified Modeling language). Application of this application there are two methods of access is through smatphone android and desktop for administrator and Study Program level. While the research was conducted at the University of Kuningan

Keywords: Lecturer Evaluation, RAD, UML, Smartphone, Android, Universitas Kuningan

\section{PENDAHULUAN}

\subsection{Latar Belakang}

Di era teknologi sekarang ini sistem operasi berkembang sangat pesat sekali, banyaknya varian sistem operasi yang diterapkan baik di personal desktop (PC) atau laptop maupun yang diterapkan pada desktop (PC) atau laptop maupun yang diterapkan pada smartphone, sehingga dengan banyaknya varian memudahkan user untuk dapat memilih sesuai kebutuhannya. Salah satu contoh sistem operasi yang diterapkan pada smartphone adalah android. Sistem operasi ini dapat digunakan di ponsel dan kompatibel dengan perangkat - perangkat keras lainnya seperti computer. Seiring pesatnya perkembangan teknologi mobile semakin banyak juga bermunculan aplikasi - aplikasi berbasis mobile yang memiliki berbagai macam fasilitas yang dapat menyediakan informasi. Pentingnya suatu sistem operasi mobile seperti android yang dapat memberikan berbagai macam kemudahan pengaksesan informasi. mobile application menjadi sarana yang sangat populer saat ini karena memnudahkan user untuk menggunkana beberapa aplikasi komputer yang biasanya harus membuka komputer ataupun laptop seperti membuka atau menulis dokumen, memutar lagu, memutar film browsing dan banyak hal yang lainnya yang dapat dilakukan di mobile application. 
Didalam organisasi pendidikan tinggi, evaluasi dosen merupakan cara untuk mengetahui pengaruh pengajaran dosen terhadap mahasiswa, yaitu proses penilaian dari persiapan mengajar, materi pembelajaran, penyampain materi ajar, kompetensi dosen, pengelolaan kelas dan evaluasi pemebelajaran. disamping penilain dari mahasiswa, penilaian dosen yang dilakukan program studi dianggap penting untuk melihat kinerja dosen yang sesuai dengan home base program studi. Pada saat ini Universitas Kuningan (UNIKU) saat ini sudah melaksanakan evaluasi dosen untuk proses belajar mengajar secara rutin melalui kuisioner yang diisi oleh mahasiswa setelah proses belajar mengajar selesai, salah satu cara yang dilakukan Universitas yaitu membagi kuisioner secara manual untuk anggkatan 2015 kebawah dan untuk 2016 keatas sudah menerapkan kuisioner online yang terdapat pada sistem Informasi Akademik Terpadu UNIKU (SIKADUKU). Untuk menghasilkan laporan evaluasi kinerja dosen pada saat ini sebagian masih dilakukan dengan cara yang sederhana yaitu dengan perhitungan manual. Namun seiring dengan jumlah mahasiswa yang kian bertambah dalam beberapa tahun terakhir, sistem tersebut tidaklah efektif. Pembangunan sistem yang terkomputerisasi diharapkan dapat lebih efektif dalam mengolah seuma data evaluasi dosen dan dapat menghasilkan laporan evaluasi kinerja dosen dan memberikan kemudahan bagi UNIKU untuk dapat meningkatkan kualitas dosen yang dimiliki. Dari permasalahan yang disampaikan diatas maka penelitian ini bermaksud membuat sebuah aplikasi berbasis mobile atau android untuk penilaian kinerja dosen di Universitas Kuningan.

\subsection{Rumusan Masalah}

Berdasar beberapa uraian latar belakang diatas maka penulis dapat merumuskan masalah, diantaranya :

1. Bagaimana menciptakan sebuah aplikasi Penilaian Kinerja Dosen berbasis android yang memudahkan mahasiswa dan program studi mengevaluasi kinerja dosen ?

2. Bagaimana merancang dan membuat aplikasi berbasis android yang dapat diakses secara online ?

3. Bagaimana cara membuat aplikasi agar perhitungan hasil evaluasi kinerja dosen dapat dihitung secara komputerisasi dan dapat menghasilkan laporan bagi pemangku kepentingngan?

\subsection{Batasan Masalah}

Agar penelitian yang dilakukan lebih terarah sesuai dengan tujuan penelitian, mudah dalam pengumpulan dan pengolahan analisa data serta menarik kesimpulan, maka batasan masalah adalah sebagai berikut :

1. Data yang diolah dari aplikasi ini adalah data dosen, data mahasiswa dan data mata kuliah.

2. Keluaran yang dihasilkan dari aplikasi yang dibangun berupa informasi nilai dan kesimpulan evaluasi mahasiswa dan program studi tentang kinerja dosen.

3. Aplikasi Penilaian Kinerja Dosen dibangun berbasis android dan web based application.

\subsection{Maksud dan Tujuan}

Maksud dan tujuan dari penelitian ini yakni membangun aplikasi Penilaian Kinerja berbasis android. Adapun tujuan yang ingin dicapai antara lain :

1. Memudahkan mahasiswa dalam penilaian dosen melaui perangkat mobile berbasis android.

2. Memanfaatkan media internet sebagai alat komunikasi yang mengkoneksikan database pada web service.

3. membuat program agar perhitungan hasil evaluasi dapat dihitung secara komputerisasi dan menghasilkan laporan untuk bagi pihak pemangku kepentingan.

\subsection{Manfaat}

Adapun manfaat yang hendak dicapai peneliti dari hasil penelitian ini adalah sebagai berikut :

1. Bagi Universitas dan Fakultas

a. Memudahkan bagi Universitas dan Fakultas untuk mengevaluasi kinerja dosen

b. Mempercepat proses pengelolaan data, laporan dan pengambilan kebijakan oleh pimpinan untuk menindaklanjuti hasil dari evaluasi tersebut.

c. Meminimalisir penggunaan kertas berlebih.

2. Bagi pihak lainnya

a. Sebagai salah satu penelitian yang dapat dikembangkan dikemudian hari

b. Dapat dijadikan rujukan atau acuan untuk penilaian kinerja karyawan atau sejenisnya.

3. Bagi Penulis

a. Sebagi salah satu bentuk wujud nyata yang dapat diimplementasikan di Universitas Kuningan

b. Menambah pengetahuan tentang manajemen mutu sumber daya manusia 


\section{Metode Penelitian}

Langkah - langkah penelitan yang dilakuan untuk menyelesaikan penelitan sebagai mana terlihat pada gambar dibawah ini :

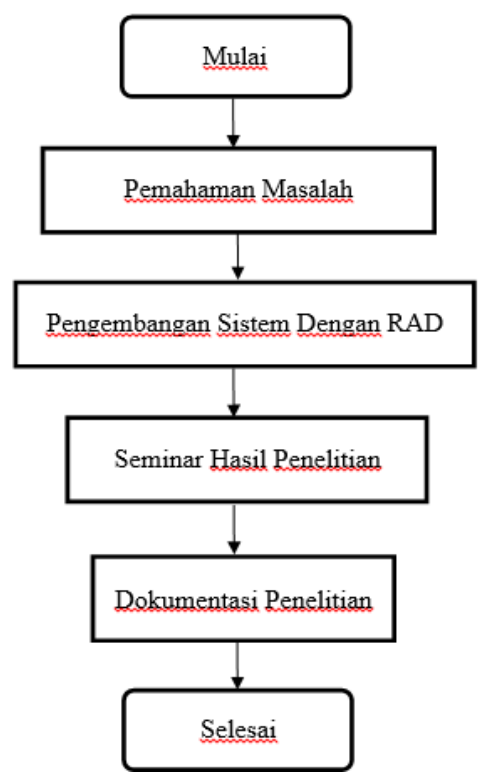

Gambar 1. Flowchart Penelitian

\subsection{Pemahaman Masalah}

Didalam organisasi pendidikan tinggi, evaluasi dosen merupakan cara untuk mengetahui pengaruh pengajaran dosen terhadap mahasiswa. Evaluasi dosen meliputi kegiatan mengumpulkan informasi mengenai bagaimana dosen melakukan pekerjaan, menginterpretasi informasi dan membuat penilaiaan mengenai tindakan apa yang harus dilakukan untuk meningkatkan kualitas pekerjaan.

Pada saat ini Universitas Kuningan sudah melaksanakan evaluasi kinerja dosen secara rutin melalui kuesioner yang di isi oleh mahasiswa pada akhir Ujian Akhir Semester(UAS). Semua kegiatan untuk menghasilkan laporan tersebut masih dilakukan dengan cara konvensional dengan cara penghitungan manual. Selain memakan waktu yang banyak, cara ini juga sangat boros karena masih menggunakan kertas dalam pengisian kuesionernya. Tak bisa dibayangkan berapa banyak kertas yang digunakan setiap pengisian kuesioner. Ditambah lagi dengan jumlah mahasiswa yang terus bertambah dalam beberapa tahun terakhir sistem tersebut sangatlah tidak efektif. Pembangunan sistem yang terkomputerisasi dan berbasis web diharapkan dapat lebih efektif dalam mengolah semua datadata evaluasi tentang dosen dan dapat menghasilkan laporan evaluasi kinerja dosen yang tepat dan cepat.

\subsection{Pengembangan Dengan Sistem RAD (Rapid Application Development) \\ Rapid Application Development (RAD)} adalah salah satu alternatif dari System Development Life Cycle digunakan untuk mengatasi keterlambatan dalam proses development. Keunggulan metode ini menggabungkan teknik SDLC,Prototyping teknik joint application development (JAD) dan computer aided software engineering (CASE Tools) yang bertujuan untuk membuat sistem dalam waktu singkat (kurang dari 6 bulan ). RAD melibatkan user pada proses desain menyebabkan kebutuhan user dapat terpenuhi dengan baik dan secara otomatis kepuasan user sebagai pengguna sistem semakin meningkat. RAD melibatkan user dalam proses testing sehingga dapat memangkas proses development yang panjang untuk dapat deliver on schedule.

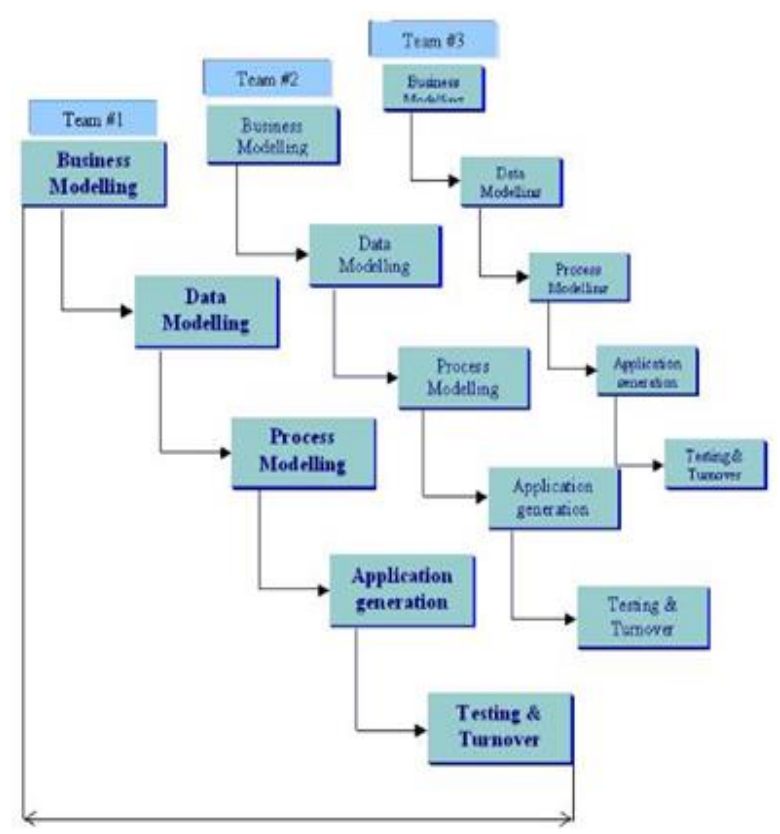

Gambar 2. Tahapan RAD (Pressman, Roger S. 2007)

\subsection{Bisnis Modeling}

Bisnis modeling memfokuskan pada pencarian informasi apa yang dibutuhkan proses bisnis, Informasi apa saja yang dihasilkan, siapa yang membuat informasi tersebut, Informasi itu dibutuhkan siapa saja dan siapa yang memproses informasi tersebut.

\subsection{Data Modeling}

Aliran informasi yang telah didefinisikan disempurnakan lagi menjadi kumpulan object 
data, yang dibutuhkan untuk mendukung sistem tersebut. Karakteristik (Atau atribut) masingmasing object diidentifikasi dan relasi antara object tersebut didefinisikan.

\subsection{Proses Modeling}

Object data yang telah didefinisikan ditransformasi untuk mendapatkan aliran informasi yang mungkin mengimplementasikan fungsi bisnis. Deskripsi proses dibuat untuk menambah, modifikasi, penghapusan, atau pencarian object data. Sistem dirancang menggunakan UML.

\subsection{Application Generation}

Pekerjaan proses RAD dilakukan dengan menggunakan kembali komponen program yang sudah ada (jika memungkinkan) atau membuat komponen yang bisa dipergunakan kembali (jika memungkinkan). Untuk itu, dibutuhkan (automated tool) untuk pembuatan software tersebut. Bahasa pemrograman yang digunakan adalah PHP dan MySQL berbasis objek.

\subsection{Testing \& Turnover}

Karena proses RAD mempergunakan kembali komponen yang sudah ada, maka beberapa komponen program telah teruji. Hal ini bisa mengurangi waktu pengujian secara keseluruhan, akan tetapi komponen harus tetap di uji. Pengujian dilakukan menggunakan pengujisn Black box (menguji kesesuaian Antara input dan output), white box (menguji validitas dari fungsi program).

\subsection{Analis Sistem Yang Sedang Berjalan}

Analis bertujuan untuk mengidentifikasi permasalahan-permasalahan yang terdapat pada sistem serta menentukan kebutuhan-kebutuhan dari sistem yang dibangun. Analisa tersebut meliputi analisa masalah, analisa kebutuhan data, dan analisa sistem.

\subsection{Sistem Berjalan}

Sistem penilaian kinerja dosen untuk mahasiswa anggkatan lama saat ini masih menggunakan selembar kuisioner yang di print out dan di fotocopy sebanyak mahasiswa dikali dosen mata kuliah yang di evaluasi. Evaluasi kinerja dosen ini rutin dilakukan sebelum melaksanakan Ujian Tengah Semester dan Ujian Akhir Semester. Untuk angkatan mahasiswa baru menggunakan kuisoner online

Penerapan untuk mahasiswa lama cara tersebut kurang efektif, mengingat bahwa anggaran yang digunakan untuk mengevaluasi kinerja dosen semakin bertambah saat mahasiswa semakin bertambah, dan pastinya membutuhkan waktu yang lama karena dihitung secara manual. Sedangkan untuk mahasiswa baru menggunakan online tetapi kendala mahasiswa tidak semuanya mempunyai computer atau laptop. System yang dikembangkan menggunakan sebuah sistem yang efektif, cepat dan mudah digunakan dalam penilaian kinerja dosen tersebut yaitu dalam sebuah aplikasi mobile. Karena dengan perangkat mobile aplikasi ini dapat digunakan kapan saja dan dimana saja asalkan terintegrasi dengan jaringan internet.

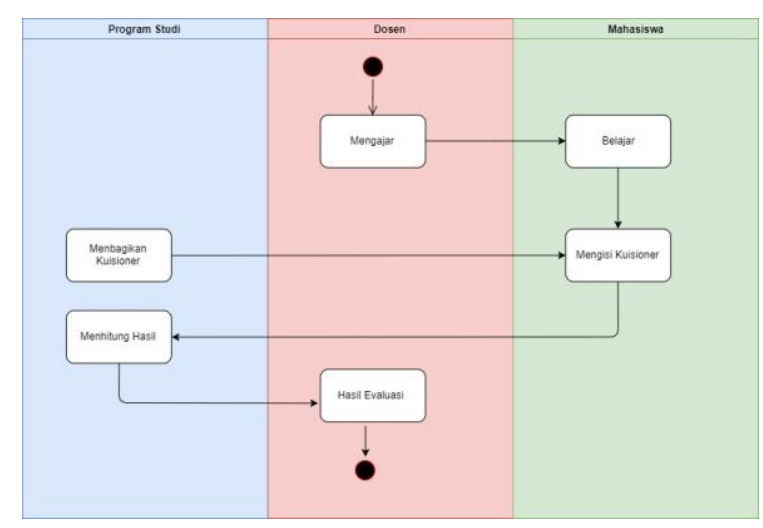

Gambar 3. Activity Diagram Berjalan

\subsection{Sistem Yang Diusulkan}

Dari hasil analisa sistem diatas penulis akan mengusulkan sistem berjalan yang secara manual menjadi sistem komputerisasi. Perubahan yang dilakukan adalah sebagai berikut:

- Mengisi Kuioner $\rightarrow$ pada sistem mengisi EDOM yang semula hanya dapat mengisi Kuioner di dalam kampus. Dengan aplikasi yang akan di buat diharapkan mahasiswa dapat mengisi Kuioner dimanapun, dan kapanpun, asalkan terkoneksi dengan internet.

- Membagikan angket $\rightarrow$ pada sistem lama Program Studi membagikan angket/ quisioner memakan banyak biaya dan banyak kertas. Dengan aplikasi yang akan di buat diharapkan dapat menghemat biaya dan kertas.

- Perhitungan $\rightarrow$ pada sistem lama hasil evaluasi dosen dihitung secara manual yang membutuhkan ketelitian dan memakan waktu yang tidak sebentar. Dengan aplikasi yang akan di buat diharapkan dapat menghemat waktu dalam menghitung hasil evaluasi. 


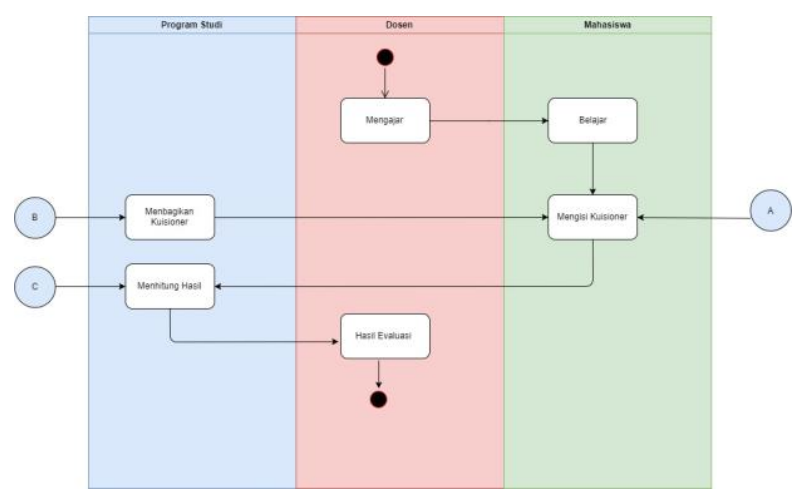

Gambar 4. Activity Diagram Yang Di Usulkan

\subsection{Use Case Diagram}

Use case diagram digunakan untuk mendeskripsikan actor atau pengguna melalui sebuah alur deskripsi bagaimana sistem tersebut dipakai.

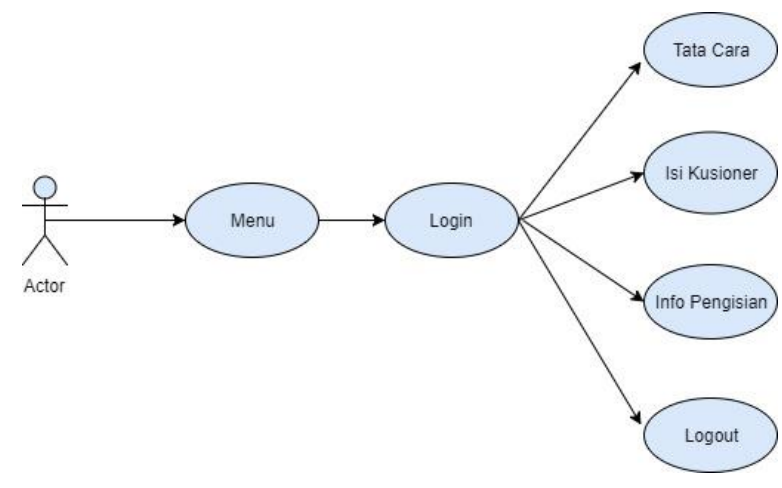

Gambar 5. Use Case Diagram

Penjelasan Use case Diagram

\begin{tabular}{|l|l|}
\hline \multicolumn{1}{|c|}{ Aktor } & \multicolumn{1}{|c|}{ Deskripsi } \\
\hline Menu & $\begin{array}{l}\text { Menampilkan menu login } \\
\text { admin dan mahasiswa }\end{array}$ \\
\hline Login & $\begin{array}{l}\text { Proses Login untuk } \\
\text { mengetahui informasi } \\
\text { identifikasi user. }\end{array}$ \\
\hline Tata Cara & $\begin{array}{l}\text { Proses melihat tata cara } \\
\text { pengisian Kuioner }\end{array}$ \\
\hline $\begin{array}{l}\text { Mengisi } \\
\text { EDOM }\end{array}$ & $\begin{array}{l}\text { Proses menampilkan } \\
\text { pertanyaan quisioner Kuioner }\end{array}$ \\
\hline Info Pengisian & $\begin{array}{l}\text { Proses menampilkan info } \\
\text { pengisian Kuioner yang telah } \\
\text { di isi }\end{array}$ \\
\hline Log Out & $\begin{array}{l}\text { Proses kembali ke menu } \\
\text { utama }\end{array}$ \\
\hline
\end{tabular}

p-ISSN : 1858-3911, e-ISSN : 2614-5405 https://journal.uniku.ac.id/index.php/ilkom

\subsection{Activity Diagram}

Activity Diagram merupakan deskripsi logika aliran kerja dari aplikasi yang akan dibangun. Pada penelitian ini activity diagram nya adalah sebagai berikut :

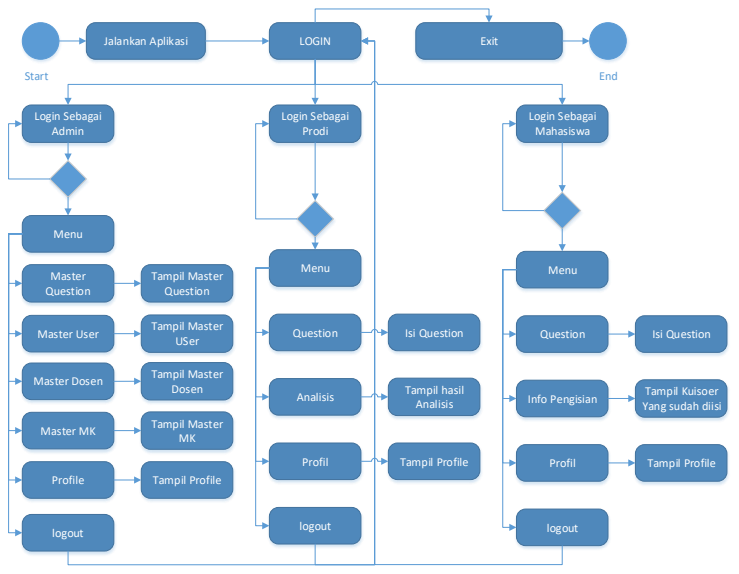

Gambar 6. Activity Diagram

\subsection{Squence Diagram}

Didalam diagram ini menjelaskan urutan proses yang dilakukan dalam sistem kerja pengisian kuisioner untuk mencapai tujuan dari use case yang telah dirancang. Pada perancangan aplikasi ini sequence diagram nya adalah sebagai berikut :

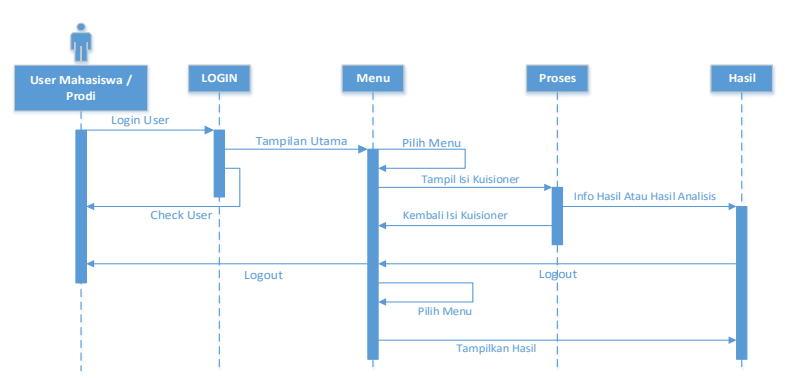

Gambar 7. Squence Diagram

\section{PEMBAHASAN}

\subsection{Spesifikasi Sistem}

\subsubsection{Perangkat Keras (Hardware)}

Dalam menerapkan dari rancangan yang telah dijelaskan sebelumnya dibutuhkan beberapa perangkat keras untuk menyajikan aplikasi ini. Adapun alat-alat yang dibutuhkan adalah:

a) Handphone Android

Dalam pengujiam program ini, penulis menggunakan handphone Android dengan spsesifikasi sebagai berikut:

1) Sistem operasi Android Ginggerbreead Or Higger 
2) $R A M 512 \mathrm{MB}$.

3) Minimal resolusi Layar 480 x 800 pixels.

b) Laptop

Adapun spesifikasi laptop yang digunakan untuk membuat aplikasi ini yaitu:

1) Intel Core i3 2,40 Ghz.

2) $R A M 6 G B$.

3) Hardisk 500GB.

4) Screen Resolusi 14 Inc (1366 x 768) pixels.

\subsubsection{Perangkat Lunak (Software)}

a) Sistem operasi Windows 7 Enterprise 64Bit.

b) Phonegap Cordova

c) Browser Chrome.

d) Plugin simulator Ripple

e) Notepad ++

f) $X A M P P$

\subsection{Prosedure Operasional}

Prosedure operasional merupakan kegiatan yang bertujuan untuk menerangkan secara singkat bagaimana penggunaan dalam mengoperasikan aplikasi ini seperti yang akan dijelaskan berikut ini:

1. Instal file evaluasi.apk di handphone Android.

2. Setelah sukses instal buka aplikasi ini, setelah itu aplikasi akan menampilkan menu utama.

3. Di menu utama akan muncul login

4. Silahkan masukkan username dan password, jika berhasil system akan menverifikasi sesuai hak aksesnya

5. Setelah selesai pilih menu logout untuk kembali ke menu login, dan pilih keluar untuk keluar dari aplikasi.

\subsection{Implementasi Sistem}

\subsubsection{Login System}

Untuk memulai aplikasi ini user akan mendapatkan tampilan login aplikasi, dimana system akan memverifikasi berdasarkan user dan selanjutnya akan ditampilkan menu - menu berdasarkan user. Berikut tamplan login aplikasi :

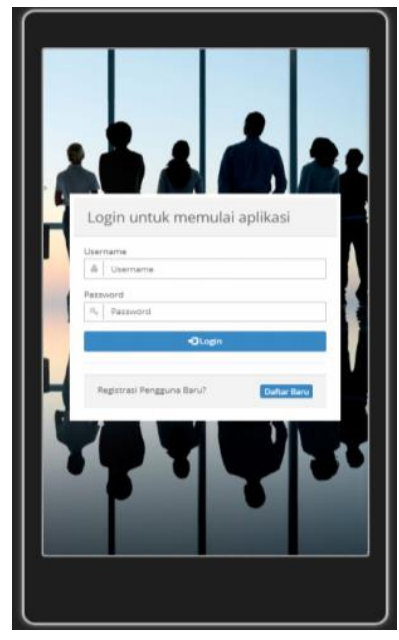

\section{Gambar 8. Login Aplikasi}

\subsubsection{Halaman Administrator}

Untuk halaman administrator ada dua pilihan akses yakni melalui browser desktop atau mobile. Dikarenakan admin akan memasukan beberapa item data, maka dipermudah aksesnya melalui browser desktop, didalam halaman Administrator terdapat menu Master Question, Master User, Master Dosen, Master MK dan Profile. Berikut tampilan masing - masing menunnya :

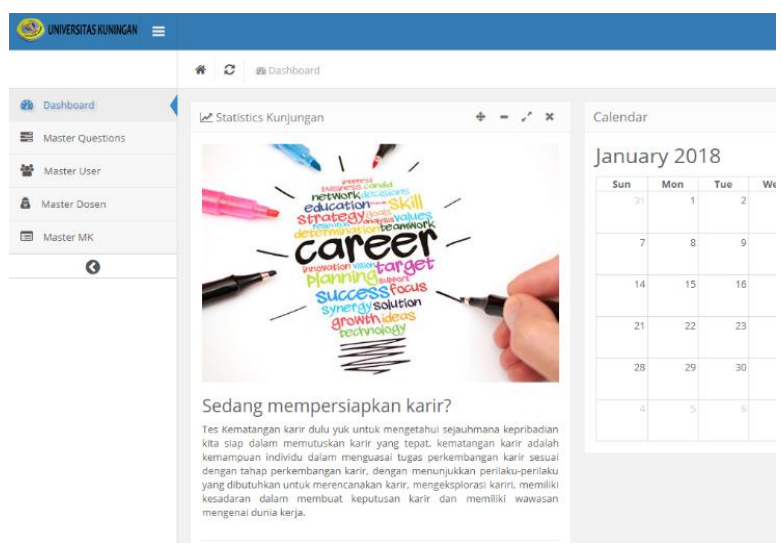

Gambar 9. Dashboard Adminstrator

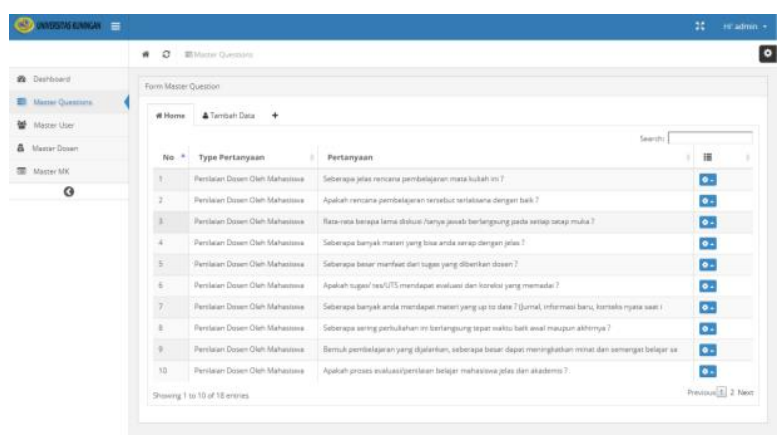

Gambar 10. Master Question

\subsubsection{Halaman Program Studi}

Untuk halaman Program Studi untuk aksesnya bisa melaui dua cara yakni melalui browser destop dan mobile. Dalam halaman ini terdapat menu Question, Analisis dan Profile. Halaman ini hampir sama dengan tampilan mahasiswa perbedaanya terdapat pada pertanyaan dan hasil evaluasi, dan tampilannya sebagai berikut : 


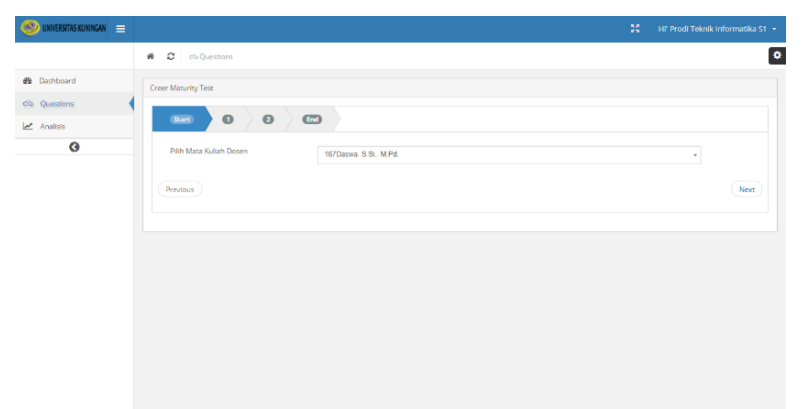

\section{Gambar 11. Evaluasi Dosen Prodi Versi Desktop}

\subsubsection{Halaman Mahasiswa}

Untuk mengakses halaman ini user wajib memdaftarkan terlebih dahulu ke dalam aplikasi dan system akan mencocokan data yang terdapat di sistem akademik Universitas. Jika terdapat verifikasi email, selanjutnya mahasiswa login dengan username dan password, dan berikut beberapa tampilan untuk user sebagai mahasiswa :

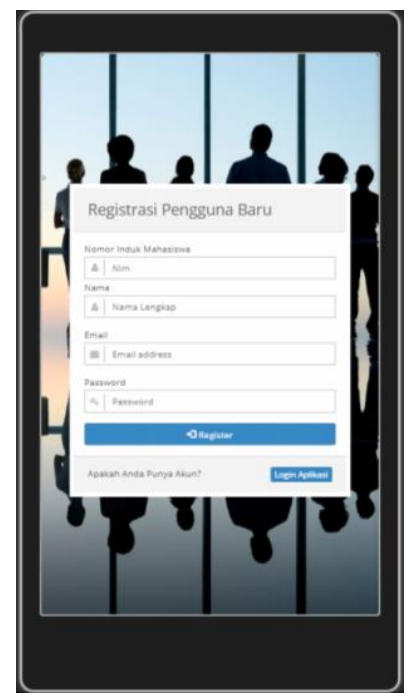

\section{Gambar 12. Halaman Registasi dan Login Mahasiswa}

\subsubsection{Halaman Pengisian Quesioner}

Pada halaman ini mahasiswa setelah login dan memilih menu Question, selanjutnya akan memilih penilaian sesuai mata kuliah yang diambil pada saat KRS selanjutnya akan dilakukan penilaian. Berikut ini tampilan jika telah memilih mata kuliah :

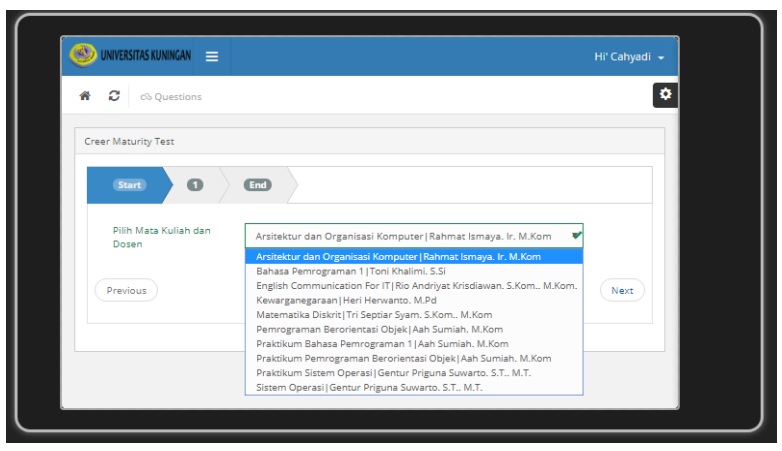

Gambar 13. Halaman Pemilihan Mata Kuliah

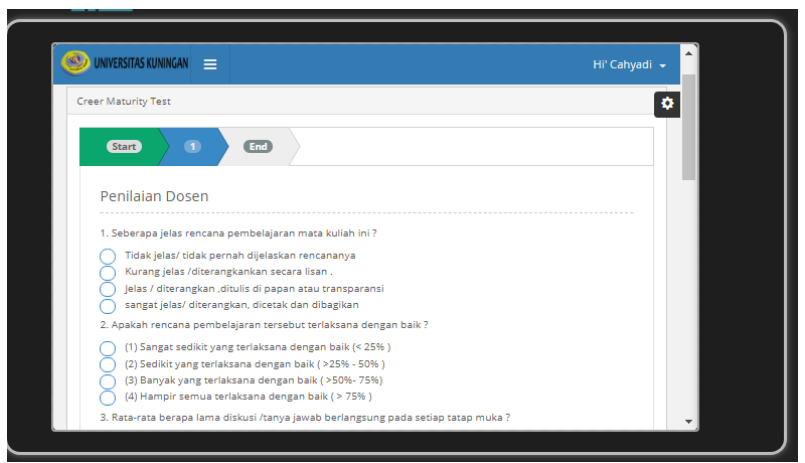

Gambar 14. Halaman Pengisian Quesioner

\section{KESIMPULAN}

Berdasarkan hasil pengujian aplikasi Evaluasi Dosen berbasis Android maka diperoleh kesimpulan sebagai berikut:

1. Aplikasi Penilaian Kinerja Dosen ini dapat di install dan berjalan di perangkat mobile berbasis Android.

2. Aplikasi Penilaian Kinerja Dosen memanfaatkan media internet dan berjalan secara online, memudahkan mahasiswa mengisi kuisioner dimana saja dan kapan saja.

3. Aplikasi Penilaian Kinerja Dosen di lengkapi dengan pehitungan hasil evaluasi secara 
JURNAL NUANSA INFORMATIKA

Volume 12 Nomor 2, Juli 2018

otomatis sehingga dapat menghemat waktu dalam perhitungan evaluasi dosen.

\section{SARAN}

Berdasarkan kesimpulan diatas, maka saran yang diharapkan adalah aplikasi Penilaian Kinerja Dosen Berbasis Android ini bisa dikembangkan lagi. Sebaiknya dikembangkan agar bisa dijalankan di multiflatfrom selain android, seperti blackberry dan windows phone.

\section{DAFTAR PUSTAKA}

[1] Doyle, Matct (2011). Master Mobile Web Apps with JQuery Mobile. Elated Communications Ltd, United Kingdom, First Edition, 2011

[2] F. Priyanta. Pemograman Android untuk Pemula, Cerdas Pustaka Publisher, Jakarta, 2011

[3] Huda, Akbarul Arif, (2012), 24 Jam Pintar Pemrograman Android, C.V Andi Offset, Yogyakarta

[4] Jogiyanto HM, (1999), Analisis \& Desain Sistem Informasi Pendekatan Terstruktur Teori dan Praktek Aplikasi Bisnis, C.V Andi Offset, Yogyakarta

[5] Roger S. Pressman, Ph. D.(2002). Rekayasa Perangkat Lunak. C.V Andi Offset, Yogyakarta

[6] Safaat, H Nazruddin (2012) Pemrograman aplikasi mobile smartphone dan tablet PC Berbasis android, Informatika Bandung

[7] Sholiq, (2006), Pomedalan Sistem Informasi Berorientasi Obyek Dengan $U M L$ : Graha Ilmu.

[8] Tutang, (2002), Membangun Jaringan Sendiri Dengan LAN, Datakom Lintas Buana, Jakarta

[9] Untung Raharjo (2009), Augury El Rayeb, Asep Saefullah, Membuat Website Dengan
p-ISSN : 1858-3911, e-ISSN : 2614-5405

https://journal.uniku.ac.id/index.php/ilkom

CSS Dan HTML, C.V Andi Offset, Yogyakarta,

[10] Kadir, Abdul. (2008) "Tuntunan Praktis Belajar Database Menggunakan MYSQL". Yogyakarta

[11] Raharjo, Budi (2007). "Pemograman $C++$ : mudah dan cepat menjadi master $c++$ ". Bandung :Informatika

[12] Nugroho, A (2005), "Rational Rose untuk Pemodelan Berorientasi Objek"; Penerbit Informatika, Bandung

[13] Whitten et all (2005), "System Analysis and Design Model”, Springfield ,USA 